\title{
Research on the Mechanism and Countermeasures of Tax Policy to Promote the Development of New Urbanization
}

\author{
Xiao-Feng ZHANG \\ School of Public Finance and Administration,Harbin University of Commerce,No. 1 Xuehai Street \\ Songbei Harbin City Heilongjiang Province 150028, China
}

zhxf928@163.com

\begin{abstract}
Keywords: New Urbanization, Tax Policy, Operation Mechanism.
Abstract. New urbanization is an important engine of future economic development, how to use the powerful tax policy to facilitate this process, it is particularly important. In the analysis of the traditional external effects of urbanization development, based on in-depth analysis of the operating mechanism of the new tax urbanization development policy, including the relationship between migration mechanism and the mechanism of taxation and the urbanization rate of new urbanization development, the proposed adjustments to the macro tax burden structure, optimize the structure of the tax system, improve the local tax system and the development of tax incentives to promote the new urbanization development countermeasures.
\end{abstract}

As the changing process of urban and rural development, urbanization has always been one focus of theorists and practitioners concerned. Tax policy as an important tool for national macroeconomic regulation and control, in the promotion of China's new urbanization development will play an important supporting role. Current research experts and scholars on the development of urbanization more, but few studies on tax policies to promote the development of new urbanization, especially the operating mechanism of the new tax policy to promote the development of urbanization less. Development of urbanization have significant external effects, and therefore need appropriate tax policies play positive externalities, correct negative externalities; Mechanism between population movements from new urbanization development mechanism, the urbanization rate of taxation and tax aspects in-depth analysis policies for the operating mechanism of urbanization development; Finally, promoting the development of new urbanization countermeasures.

\section{The external effect of the traditional urbanization development}

\section{The positive external effect of the traditional urbanization development}

Positive external effects caused by traditional development of urbanization is enormous, on the one hand to promote the comprehensive development of urban areas can generate aggregate economic resources, changes in consumption concept, promote technological innovation, improve infrastructure and increase employment awareness positive externalities; on the other hand, also contributed to the prosperity and development of rural areas, to solve the current "three rural" issue an important positive role, including the promotion of the industrialization of agriculture, farmers' concept of change, the integration of urban and rural resources and environmental protection and increase the farmers' income. Former State Planning Commission Economic Planning Division, "suggested that the Chinese urbanization process" that read: From 2001 to 2015, China's urbanization rate increase of 1 percentage point per year (not including natural urban population increase of 40 million), It will make 250 million rural population into urban residents around. The actual show: from 2001 to 2015, 14 years, large-scale farmers into the public, so that the survival of the majority of migrant workers, lifestyle and entertainment choices undergone tremendous change, promoting a significant change of economic pattern. ${ }^{[1]}$

The negative external effect of the traditional urbanization development

While traditional urbanization can bring a lot of positive external effects, but it can also produce some negative external effects, to the city and residents of introducing additional hazards and 
problems. Governance and how to correct these problems, the key is to find out why. Traditional negative external effects caused by the development of urbanization mainly in: farmers and the widening gap between rich and poor people, urban ecological imbalance, engineering development environment, urban crime rates rise and lack of social security system, etc., and thus bring culture, education, resources, transportation and housing and other issues. Since the process of urbanization development of environmental resources of the public and lead to unclear property rights is to produce negative external effects of the root causes, and all aspects of government policy failure is the direct cause of negative externalities. ${ }^{[2]}$

From the above analysis we can see, there are many positive externalities and negative externalities of traditional urban development, which is to develop and implement tax policy to provide space. Tax policy can give positive externality subsidies can be negative externalities timely correction and ultimately new urbanization development.

\section{The operating mechanism of the tax policy of new urbanization development}

\section{The mechanism of population flow in the development of new urbanization}

One of the main features of the town is the massive growth of urban population. Overseas Research on migration, including migration and urbanization, Basic reasons, influencing factors, spatial characteristics and policy research; and our research include population mobility and urbanization relationship, influencing factor, regional impact, as well as statistics migrants context attribute and spatial distribution.

China Modern Urban Research Center Ding Jinhong (2005) believes that Chinese migration into a new phase of high activity, high capacity, the growing imbalance; NDRC cities and small towns reform and development center Zheng bright (2006) constructed the county population gravity model migration, and to evaluate the potential and attract the largest possible population migration destination township population distribution and the like. Based on China's national conditions, combined with China's urbanization actual development, we believe that the impact of urban development of population mobility factors include: the distance of Rural and urban real income gap between expected income level of rural and urban areas, urban areas level of employment, and tax policy, child education emphasis and health conditions. ${ }^{[3]}$ If $t$ represents time in the total number of rural population to urban mobility, it is a function of all factors combined, can create a formula as follows:

$$
Y_{t}=F\left(a W_{u}-a W_{r}-k D-T-\Delta C\right)
$$

Wherein: the above $a$ represents the future income equivalent to the current expected rate of return on revenue, $W_{u}$ represents the real income of urban residents, $W_{r}$ rural residents on behalf of real income, $a W_{u}$ expected income on behalf of the farmers into the city, $a W_{r}$ on behalf of the rural farmers are still expected income, $k$ representing the transport cost factor, $D$ representing distance between rural and urban, $T$ on behalf of the farmers into the city may incur taxes, $\Delta C$ on behalf of the farmers the difference between the cost of other factors arising after the city. Therefore, when the expected revenue growth greater than all costs arising from migration, rural towns may flow, which requires, $a W_{u}-a W_{r}-k D-T-\Delta C>0$ or otherwise people will stop flowing to the countryside.

\section{The relationship between tax and urbanization rate}

Here you can analyze the changes urbanization rate from a tax perspective. Factors that affect the rate of urbanization include: Transference levels between rural and urban economic factors, represented by $\mathrm{E}$; economic level of industrialization, represented by $\mathrm{C}$; urban industrial structure transformation level, denoted by I; the level of agricultural mechanization in rural areas, with M FIG. We believe that the urbanization rate (expressed in $\mathrm{U}$ ) is $\mathrm{E}, \mathrm{C}, \mathrm{I}$ and $\mathrm{M}$ function is expressed as:

$U=F(E, C, I, M)$

These four factors for the development of urbanization has a positive effect, it is: $\frac{\partial U}{\partial E}>0, \frac{\partial U}{\partial C}>0, \frac{\partial U}{\partial I}>0$, $\frac{\partial U}{\partial M}>0$, Then there is the total differential: $d U=\frac{\partial U}{\partial E} d E+\frac{\partial U}{\partial C} d C+\frac{\partial U}{\partial t} d t+\frac{\partial U}{\partial M} d M>0$, 
It can be seen: the level of urbanization is economic factors U Transference level E, the economic level of industrialization $\mathrm{C}$, urban industrial structure transformation level I and rural agricultural mechanization $\mathrm{M}$ monotonically increasing function.

But tax policy on urbanization level has a greater impact, mainly in: internal guide urban residents through different types of tax policies and efforts to geographical distribution patterns and adjust the industrial structure of economic agents; ${ }^{[4]}$ Effects gathered through the town, and then affect the level of industrialization and urbanization; and through its impact on agricultural machinery and agricultural products processing, thereby affecting the level of agricultural mechanization in rural areas. Here the impact of tax policy analysis on the urbanization rate of four factors which affect the rate of urbanization is the tax policy ( $T$ representation) function, were set:

$E=\mathrm{f}_{1}(\mathrm{~T}), C=\mathrm{f}_{2}(\mathrm{~T}), I=\mathrm{f}_{3}(\mathrm{~T}), M=\mathrm{f}_{4}(\mathrm{~T})$

And $\mathrm{T}$ promote the role of both, but they hinder. Therefore, the urbanization rate $U$ function can be expressed as: $U=F\left[f_{1}(T), f_{2}(T), f_{3}(T), f_{4}(T)\right]$, Then:

$\frac{\partial U}{\partial T}=\frac{\partial U}{\partial E} \frac{\partial E}{\partial T}+\frac{\partial U}{\partial C} \frac{\partial C}{\partial T}+\frac{\partial U}{\partial I} \frac{\partial I}{\partial T}+\frac{\partial U}{\partial M} \frac{\partial M}{\partial T}$

Tax policy by influencing the E, C, I and M, which affects the rate of urbanization U, which affect the results mainly for the following different situations and development model:

First, when $\frac{\partial E}{\partial T}>0, \frac{\partial C}{\partial T}>0, \frac{\partial I}{\partial T}>0, \frac{\partial M}{\partial T}>0$, Namely the transfer of tax policies favor the flow of economic factors, industrialization and economic development, urban and rural industry structural changes to improve agricultural mechanization, the rapid development of urbanization will be expressed as "the synchronization of urbanization."

Second, when $\frac{\partial C}{\partial T}>0, \frac{\partial I}{\partial T}>0, \frac{\partial E}{\partial T}<0, \frac{\partial M}{\partial T}<0$, That tax policy conducive to economic development and industrialization of urban industrial structure change, but not conducive to divert the flow of economic factors and rural agricultural mechanization, the urbanization development will be hindered in the external environment, the performance of "lag urbanization."

Third, when $\frac{\partial C}{\partial T}<0, \frac{\partial I}{\partial T}<0, \frac{\partial E}{\partial T}>0, \frac{\partial M}{\partial T}>0$, That tax policy is not conducive to economic development and industrialization of urban industrial structure change, but the flow of economic factors in favor of the transfer of rural and agricultural mechanization, the urbanization development will be hindered on the internal development environment, the performance of "false urbanization."

Fourth, when $\frac{\partial E}{\partial T}<0, \frac{\partial C}{\partial T}<0, \frac{\partial I}{\partial T}<0, \frac{\partial M}{\partial T}<0$, that tax policy is not conducive to divert the flow of economic factors, industrialization and economic development, urban and rural industry structural changes to improve agricultural mechanization, the tax policy will be completely hinder the development of urbanization, the performance of "emptiness urbanization . "

\section{Promote the development of new urbanization tax policy}

\section{Structural adjustment of macro tax burden}

One unified urban and rural tax system. Alleviate rural areas, agriculture and farmers' burden, and gradually the farmers and agricultural production are included in the scope of personal income tax and VAT for agricultural production more preferential VAT policy. Second, balance the tax burden industry. As established mechanisms to promote farmers' income tax, reduce the tax burden of the tertiary industry and urbanization process in the nascent service industry to give more tax breaks. Third, adjust the tax area. Construction of industry-oriented tax system, adhere to the direct and indirect preferential concessions combined indirect promotions based. Should gradually weaken long-term-oriented preferential taxation policies in the region, strengthen industry-oriented. ${ }^{[5]}$

\section{Optimizing the structure of the tax system}

First, to further optimize the existing urban tax system. The property tax, land use tax, deed tax, vehicle and vessel usage tax or property tax reform and property-related taxes as a priority, so that gradually become the main town taxes, provide financial support to urban public services; the urban construction tax and education surtax as independent taxes, raise special development fund. The second is to use tax policy to promote sustainable urban development. Including the optimization of 
the existing personal income tax system, the tax rate is changed, the timely introduction of social security tax, levy a specific urban public facilities use tax.

\section{Improve the local tax system}

At present, China's local tax system at present, China's local tax system taxes in larger quantities, but the lack of stable sources of tax revenue, income taxes ample body, which is an important cause of weak local financial resources, urban infrastructure, incomplete coverage of basic public services . Therefore, it must rational allocation between central and local government taxes, local governments also have to ensure that some of the sources of tax revenue is relatively concentrated, stable and relatively convenient collection, sufficient income, the larger the potential income tax as the main tax. According to international experience, we should set up a business tax, property tax as the main tax local tax system. In addition, you can be certain goods and services tax, income tax and other under local, such as local corporate income tax (corporation tax), personal income tax and local taxes and other local resources. ${ }^{[6]}$ Or timely introduction of new taxes, such as social security taxes, environmental taxes.

\section{Develop tax incentives}

First, the development of industry tax incentives. Including the development of agricultural industrialization, the development of secondary industry, tertiary industry development tax incentives. Second, the use of tax incentives to promote sustainable development. Including full play to the role of tax regulation, and promote urban employment, drawing on the useful experience of foreign countries, air pollution, water pollution and urban environmental pollution behavior assessment, in order to reduce labor taxes, improve environmental quality and reduce unemployment; at the same time, related to environmental protection industry tax breaks and other tax incentives, to reduce their production costs, and indirectly to adopt environmentally friendly behaviors compensation.

\section{Acknowledgement}

This research was financially supported by the Heilongjiang Social Science Fund Project "Study on the fiscal policies to promote the development of the new-style urbanization in Heilongjiang" (16JYC09) and Harbin University of Commerce Youth Innovation Talent Support Project "study on fiscal policy innovation and mechanism of the new-style urbanization development" (2016QN003)

\section{References}

[1] United Nations World Urbanization Prospects: The 1994 Revision [M], New York: United Nations, 1995.

[2] Huang Xianming, Xiao Taishou The current new town development and taxation problems [J]. Economic Research, 2015, (06)

[3] Xu middle, Zhang Xiaode tax economics [M] Beijing: National School of Administration Press, 2005, (11).

[4] governing China, Jiang long stream of new town construction in the county financial security and ease pressure Countermeasures [J]. Fiscal Studies, 2015, (07)

[5] Near Chen Long, Zhang. New urbanization and support cross-regional labor allocation tax policies [J]. Local Fiscal Studies, 2016, (03).

[6] Wang Shuguang tax policy analysis and recommendations [J]. Promote the development of urbanization. The Administration of China, 2015, (09) 